\title{
In vitro Evaluation of Various Culture Media for Growth of Colletotrichum graminicola causing Anthracnose of Sorghum
}

\author{
K.A. Rewale ${ }^{*}$, R.W. Deshmukh, S.M. Wahul and R.P. Bhosale \\ Department of Plant Pathology, College of agriculture, Vasantrao Naik Marathwada Krishi \\ Vidyapeeth, Parbhani (MH), India \\ *Corresponding author
}

\section{A B S T R A C T}

Anthracnose incited by Colletotrichum graminicola (Ces) Wils. is one of the most destructive and wide spread disease, causing yield losses of 21-70 per cent. The fungus $C$.

Keywords

Colletotrichum graminicola, Culture media, Sorghum

\section{Article Info}

Accepted: 12 September 2018 Available Online: 10 October 2018 graminicola cause anthracnose and leaf blight disease in sorghum. Sorghum plants affected with $C$. graminicola show small red coloured spots on both surface of leaf; the centre of the spot is white in colour encircled by red, purple or brown margins. Numerous small black dots are seen on the white surface of the lesions which are the fruiting bodies (acervuli) of the fungus. Many lesions coalesce and kill large leaf portion, in midrib region elongate elliptical, red or purple regions with black acervuli are formed. Stalk and inflorescences infection can be characterized externally by the development of circular canker. To check the growth of pathogen on various culture media total of eight culture media viz., the most suitable media were Potato dextrose agar with maximum radial mycelia growth $(89.00 \mathrm{~mm})$, followed by media Sorghum stem extract agar $(79.66 \mathrm{~mm})$, Sorghum root extract agar $(76.00 \mathrm{~mm})$ and Oat meal agar $(70.00 \mathrm{~mm})$. The colonies produced were mostly dirty white. Potato dextrose agar, Sorghum stem extract agar and Sorghum root extract agar recorded excellent $(++++)$ conidial production, whereas, it was Good $(+++)$ on Corn meal agar, Richard's agar and Oat meal agar.

\section{Introduction}

Sorghum (Sorghum bicolor (L.) Moench) is the most important cereal crop cultivated in the country after rice and wheat. Sorghum is affected by several plant pathogens including fungi, bacteria and viruses. Some of the important diseases of sorghum are: Anthracnose, Grain smut, Charcoal rot, Grain mould, Gray leaf spot, Rust and Downy mildew. (Anonymous, 2013). Powell et al., (1977) reported that grain yield was reduced by $70 \%$ and more than half the yield loss resulted from incomplete grain fill as verified by $42 \%$ decrease in 1000-seed mass and $17.2 \%$ decrease in seed density. Uttarakhand has been identified as hot spot for the anthracnose disease (Singh and Singh 2008). Anthracnose of sorghum was first reported from Togo in 1902 (Mughogho, 1988). During the investigations on anthracnose of sorghum caused by Colletotrichum graminicola (Ces) Wils. Of Sorghum (Sorghum bicolor (L.) Moench), various experiments were conducted 
at the Department of Plant Pathology, College of Agriculture, VNMKV, Parbhani.

\section{Materials and Methods}

Potato dextrose agar (PDA) was used as basal culture medium for isolation, purification and maintenance of the pure culture of $C$. graminicola. For studying cultural characteristics of $C$. graminicola, synthetic readymade (make: Hi media) and nonsynthetic (prepared) media were used. The synthetic media and ingredients of nonsynthetic media were obtained from the Department of Plant Pathology, College of Agriculture, VNMKV, Parbhani. A total of eight culture media viz., Potato dextrose agar, Richard's agar, Conn's agar, Soybean meal agar, Oat meal agar, Czapek'sdox agar, Sorghum root extract agar (10\%) and Sorghum stem extract agar (10\%) were used to study their effect on growth. Autoclaved and cooled media were poured (@20 $\mathrm{ml} /$ plate) in sterilized glass Petri plates (90 $\mathrm{mm}$ dia.) and allowed to solidify at room temperature. On solidification of the media, plates of each culture medium (three plates/medium/ replication) were inoculated by placing at the centre a $5 \mathrm{~mm}$ mycelial disc of actively growing 7 days old pure culture of C. graminicola, each medium was replicated thrice and plates were incubated at $28+2^{\circ} \mathrm{C}$ for a week.

\section{Experimental details}

Design: CRD

Replications: Three

Treatments: Eight (Culture media)

\section{Treatment details}

$\mathrm{T}_{1}$ : PDA

$\mathrm{T}_{2}$ : Richard's Agar

$\mathrm{T}_{3}$ : Conn's Agar

$\mathrm{T}_{4}$ : Soybean Meal Agar
$\mathrm{T}_{5}$ : OatMeal Agar

$\mathrm{T}_{6:}$ Czapek'sDox Agar

$\mathrm{T}_{7}$ : Sorghum Root Extract Agar (10\%)

$\mathrm{T}_{8}$ : Sorghum Stem Extract Agar (10\%)

The observations on radial mycelial growth/colony diameter $(\mathrm{mm})$, colony color and colony morphology were recorded at week.

\section{Results and Discussion}

\section{Effect of culture media}

Cultural characteristics viz., colony diameter, mycelial growth and conidial formation of $C$. graminicola were studied in vitro using 8 culture media and the results obtained are presented in Table 1 and depicted in PLATE I and Figure 1.

\section{Mycelial growth}

The results (Table 1, PLATE-I and Fig. 1) revealed that all the eight culture media tested encouraged better growth and variable conidial formation of $C$. graminicola. The mean colony diameter/ mycelial growth recorded with all test media ranged from 33.66 $\mathrm{mm}$ (Soybean meal agar) to $89.00 \mathrm{~mm}$ (Potato dextrose agar). However, significantly highest mean mycelial growth $(89.00 \mathrm{~mm})$ was recorded on Potato dextrose agar. The second and third best media found were Sorghum stem extract agar $(79.66 \mathrm{~mm})$ and Sorghum root extract agar $(76.00 \mathrm{~mm})$. This was followed by Oat meal agar $(70.00 \mathrm{~mm})$, Conn's agar (63.33 mm), Richards agar (56.33 $\mathrm{mm})$, Czapek'sdox agar $(43.00 \mathrm{~mm})$ and Soybean meal agar $(33.66 \mathrm{~mm})$.

\section{Cultural characteristics}

All the culture media tested exhibited varied cultural characteristics of the test pathogen (PLATE I). Most of the media gave colony 
growth intermixed black and white, with fluffy raised irregular growth and light pink pigmentation. The time required for initiation of the conidial formation ranged from 7 to 12 days of incubation. However, it was minimum (7 days) with the culture media Potato dextrose agar. This was followed by Sorghum root and Sorghum stem extract agar (each 8 days); Soybean meal agar and Richard's agar (each 9 days) and Czapek's dox agar (10 days).

Maximum time of about 12 days for conidial production was recorded with the culture media viz., Conn's agar and Oat meal agar.
$\mathrm{T}_{1}: \mathrm{PDA}$

$\mathrm{T}_{2}$ : Richard's Agar

$\mathrm{T}_{3}$ : Conn's Agar

$\mathrm{T}_{4}$ : Soybean Meal Agar
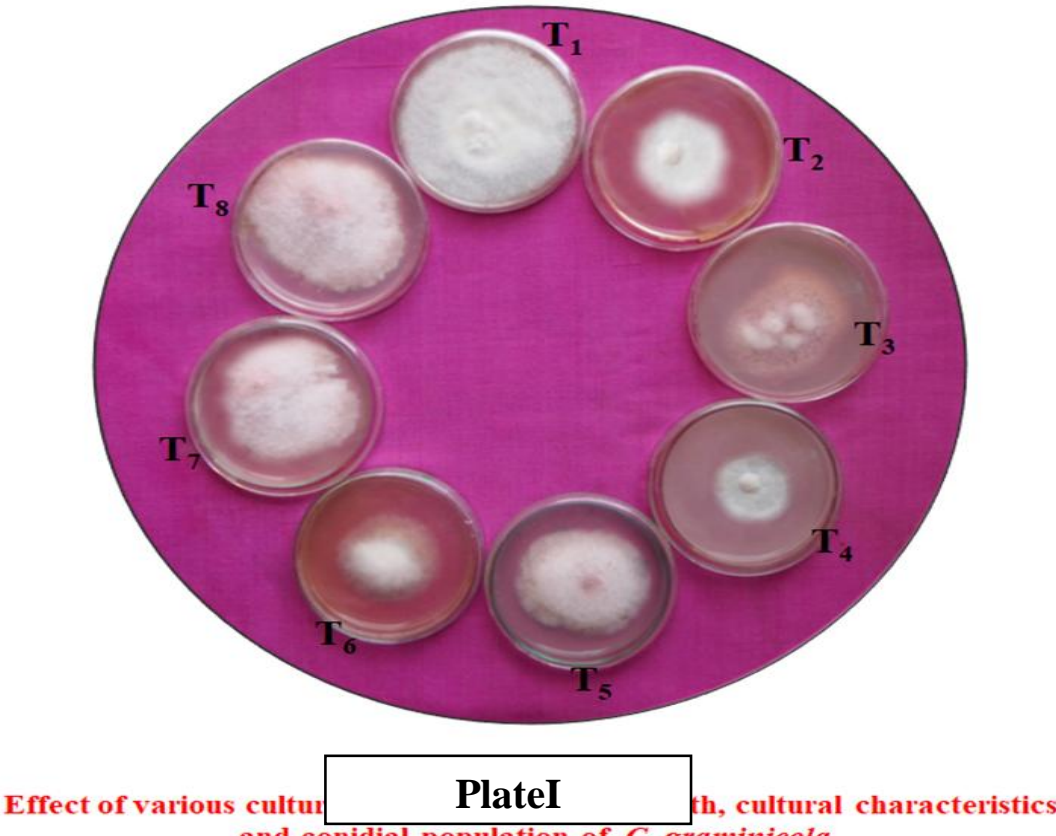
and conidial population of C. graminicola

$\mathrm{T}_{5}$ : OatMeal Agar

$\mathrm{T}_{6:}$ Czapek'sDox Agar

$\mathrm{T}_{7}$ : Sorghum Root Extract Agar (10\%)

$\mathrm{T}_{8}$ : Sorghum Stem Extract Agar (10\%)

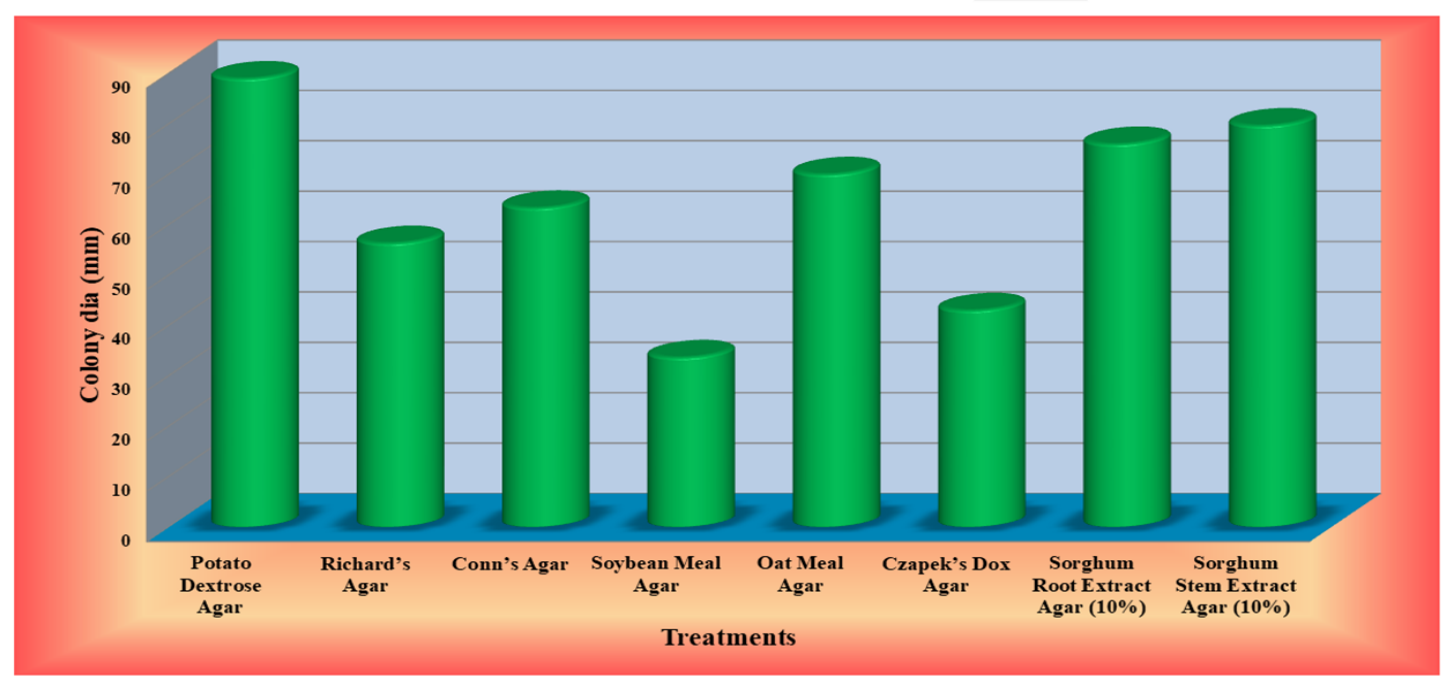

Fig.1: Effect of different culture media on mycelial growth of C. graminicola 
Table.1 In vitro effect of various culture media on mycelial growth, cultural characteristics and conidial population of C.graminicola

\begin{tabular}{|c|c|c|c|c|}
\hline $\begin{array}{l}\text { Tr. } \\
\text { No. }\end{array}$ & Treatments & $\begin{array}{l}\text { Colony } \\
\text { Dia. } \\
(\mathbf{m m}) *\end{array}$ & Cultural characteristics & $\begin{array}{c}\text { Conidial } \\
\text { populatio } \\
\text { n }\end{array}$ \\
\hline $\mathbf{T}_{1}$ & $\begin{array}{l}\text { Potato Dextrose } \\
\text { Agar }\end{array}$ & 89.00 & $\begin{array}{l}\text { Intermixed black and white, with } \\
\text { fluffy raised irregular growth light pink } \\
\text { pigmentation }\end{array}$ & ++++ \\
\hline $\mathbf{T}_{2}$ & Richard's Agar & 56.33 & White, fluffy raised irregular growth & +++ \\
\hline $\mathbf{T}_{3}$ & Conn's Agar & 63.33 & White, fluffy raised irregular growth & +++ \\
\hline $\mathbf{T}_{4}$ & Soybean Meal Agar & 33.66 & White, fluffy raised irregular growth & + \\
\hline $\mathbf{T}_{5}$ & OatMeal Agar & 70.00 & White, fluffy raised irregular growth & +++ \\
\hline $\mathrm{T}_{6}$ & Czapek'sDox Agar & 43.00 & $\begin{array}{l}\text { Intermixed black and white, with } \\
\text { fluffy raised irregular growth light pink } \\
\text { pigmentation }\end{array}$ & ++ \\
\hline $\mathbf{T}_{7}$ & $\begin{array}{l}\text { Sorghum Root } \\
\text { Extract Agar } \\
(\mathbf{1 0 \% )}\end{array}$ & 76.00 & $\begin{array}{l}\text { Intermixed black and white, with } \\
\text { fluffy raised irregular growth light pink } \\
\text { pigmentation }\end{array}$ & ++++ \\
\hline $\mathbf{T}_{8}$ & $\begin{array}{l}\text { Sorghum Stem } \\
\text { Extract Agar } \\
(\mathbf{1 0 \% )}\end{array}$ & 79.66 & $\begin{array}{l}\text { Intermixed black and white, with } \\
\text { fluffy raised irregular growth light pink } \\
\text { pigmentation }\end{array}$ & ++++ \\
\hline & S.E. \pm & 0.67 & -- & -- \\
\hline & C.D. $(P=0.01)$ & 2.81 & -- & -- \\
\hline
\end{tabular}

*Mean of three replications, $+=$ Poor,$++=$ Fair,$+++=$ Good, and $++++=$ Excellent

\section{Conidial formation}

All the eight culture media tested exhibited varied conidial production. However, Potato dextrose agar, Sorghum root extract agar and Sorghum stem extract agar recorded excellent $(++++)$ conidial production. Good (+++) conidial production was recorded on Conn's agar, Richard's agar and Oat meal agar. The media viz., Czapek's dox agar exhibited fair $(++)$ conidial production; it was poor $(+)$ on Soybean meal agar. Results of the present study on the effect of various culture media on cultural characteristics and conidial population in $C$. graminicola are in consonance with those reported earlier by several workers (Minussi and Kimati, 1978; Chacko et al., 1978; Saifulla and Ranganathaiah, 1988 and Mandeep and Munshi, 2003).
All the eight culture media tested exhibited better mycelial growth and excellent conidial production $C$. graminicola. However, the most suitable media were Potato dextrose agar with maximum radial mycelia growth $(89.00 \mathrm{~mm})$, followed by media Sorghum stem extract agar $(79.66 \mathrm{~mm})$, Sorghum root extract agar $(76.00 \mathrm{~mm})$ and Oat meal agar $(70.00 \mathrm{~mm})$. The colonies produced were mostly dirty white. Potato dextrose agar, Sorghum stem extract agar and Sorghum root extract agar recorded excellent (++++) conidial production, whereas, it was Good $(+++)$ on Corn meal agar, Richard's agar and Oat meal agar.

\section{References}

Anonymous, (2013). Indian statistical database 
Anonymous, (2014). Indian statistical database

Chacko, S., Khare, M. N. and Agrawal, S. C. (1978). Variation in growth and morphological characters of two isolates of Colletotrichum dematium f. sp. truncatum from soybean. Ind. Phytopath. 31: 261-262.

Chohan, J. S., (1967). Anthracnose disease of jowar (Sorghum vulgare Pers.) caused by Colletotrichum graminicolum (Ces.) Wils.in the Punjab. Journal of Research (PAU), 4: 394-400.

Mandeep, R. and Munshi, G. D. (2003). Effect of different culture media on the development and sporulation of Phomopsissojae and Colletotrichum truncatum. Pl. Dis. Res. 18 (1): 60-62.

Sharma, R. and Kaushal, R. P. (1999).Characterization of pathogenic variability in $C$. truncatum in Himachal Pradesh. Ind. Phytopath. 52(4): 389392.

Thesis, Univ. Agric. Sci. Bangalore, Karnataka, India.

Wijesekara, H. T. and Agarwal, D. K. (2006). Taxonomic studies on five species of the genus Colletotrichum. Ind. Phytopath. 59(2): 203-209.

\section{How to cite this article:}

Rewale, K.A., R.W. Deshmukh, S.M. Wahul and Bhosale, R.P. 2018. In vitro Evaluation of Various Culture Media for Growth of Colletotrichum graminicola causing Anthracnose of Sorghum. Int.J.Curr.Microbiol.App.Sci. 7(10): 1579-1583.

doi: https://doi.org/10.20546/ijcmas.2018.710.177 